\title{
EDUCOMUNICAÇÃO: PRÁTICAS E DESAFIOS DO USO DO RÁDIO NAS ESCOLAS ROTARY E MADRE IMACULADA, EM SANTARÉM
}

\section{EDUCOMUNICATION: PRACTICES AND CHALLENGES OF RADIO USE IN ROTARY AND MADRE IMACULADA SCHOOLS, IN SANTARÉM}

\section{EDUCOMUNICACIÓN: PRÁCTICAS Y RETOS DEL USO DE RADIO EN LAS ESCUELAS ROTARY Y MADRE IMACULADA, EN SANTARÉM}

O rádio, um dos meios de comunicação mais antigo e popular da sociedade, já nasceu com o propósito de informar e educar a sociedade, através de programas educativos. Os fundadores da mídia no Brasil defendiam que o rádio fosse a escola dos que não tinha escola e o jornal dos que não sabiam ler. E este propósito foi alcançado com os primeiros programas que levavam aos ouvintes, além de música, aulas de diversas disciplinas como inglês, português, biologia e outros. A história da radiodifusão no Brasil faz referência a inúmeros projetos que utilizaram o rádio como recurso pedagógico, os quais por meio de aulas radiofônicas ensinaram muitos jovens a ler, escrever e pensar criticamente sobre o que acontecia na sociedade. Um dos programas que perdurou durante alguns anos e foi inspiração para muitos é o Movimento de Educação de Base (MEB), o qual contribuiu para a criação de emissoras de rádios em áreas distantes do Brasil, como a Amazônia. Na região, onde as distâncias são grandes e os recursos tecnológicos como TV e a internet são

Submetido em: 26/10/2020 - Aceito em: 10/12/2020 - Publicado em: 24/12/2020

\footnotetext{
${ }^{1}$ Professora do Centro Universitário da Amazônia (Unama-Santarém). Mestre em Educação (PPGE/ Universidade Federal do Oeste do Pará - UFOPA), especialista em Jornalismo Científico (UFOPA) e em Ensino de Língua Portuguesa e Literatura (Universidade Federal do Pará (UFPA) - Campus Santarém) e Graduada em Letras (UFPA/Campus Santarém). É Gestora da Rede de Notícias da Amazônia e Educomunicadora no Projeto Escola D'água. Membro do grupo de pesquisa OFICIBER - Oficinas em cibercultura E-mail: joelmaviana@gmail.com Lattes: http://lattes.cnpq.br/4369918538261467
} 


\section{Revista Docência e Cibercultura}

escassos, o rádio tem uma importância significativa para entreter, informar e educar. Além disso, o rádio é acessível e barato e pode ser levado a qualquer lugar, mesmo onde não há energia elétrica, e sua linguagem é simples permitindo que qualquer pessoa possa entender o que está sendo dito. E inspirados nos primeiros projetos de rádio educativo, muitas escolas hoje optaram por utilizar a mídia como recurso pedagógico, através de ações educomunicativas. A educomunicação não diz respeito à educação formal, mas a um campo de atuação na interface educação e comunicação que pode favorecer o diálogo com o social e com o educativo. Nesta perspectiva a educomunicação é a gestão compartilhada de saberes que envolve tanto os professores e alunos, quanto os pais, a comunidade escolar e a comunidade no entorno das escolas. O lócus da pesquisa é a cidade de Santarém, município localizado no Oeste do Pará, como cerca de 300 mil habitantes. A escolha se deu devido ao registro de projetos educativos através do rádio. $\mathrm{O}$ primeiro surge a partir da fundação da Rádio Rural de Santarém, em 1964, pelo então bispo Dom Tiago Ryan, que tinha o pensamento de levar por meio do programa radiofônico do MEB, educação àqueles lugares distantes, onde as pessoas não tinham oportunidade de estudar na escola regular, e eram analfabetas. Após o encerramento do projeto, em 1999 foi implantado o Projeto Rádio Pela Educação de iniciativa da então jornalista Cíntia Camargo, com o apoio financeiro do Fundo das Nações Unidas para a Infância (Unicef), que tinha o objetivo de contribuir para a qualidade de educação no ensino fundamental a partir de processos de educomunicação, fomentados pela mídia rádio. A iniciativa inspirou muitas escolas a implementarem em seus espaços rádios escolares, as quais segundo Baltar (2012, p. 35) permitem inserir toda a comunidade escolar num debate permanente com o propósito de promover uma comunicação verdadeiramente emancipadora, em que de o aluno participe do processo, não apenas como receptor, mas como protagonista de seu conhecimento. Diante do exposto, optou-se por investigar o uso do rádio como recurso pedagógico nas escolas de Santarém a partir do diálogo entre comunicação e educação, com o objetivo de investigar se o rádio ainda apresenta potencialidades como recurso pedagógico em sala de aula, na interface comunicação/educação, denominada de educomunicação. Da mesma forma, buscou-se compreender como as ações são 
desenvolvidas e como os estudantes envolvidos no processo são os protagonistas. Para a obtenção dos dados, inicialmente pensou-se em fazer um estudo de caso nas escolas da rede municipal de ensino de Santarém, que trabalhavam com o rádio na escola, mas devido à ausência de dados na Secretaria Municipal de Educação de Santarém, e muitas escolas, mesmo com equipamentos instalados, terem encerrados as atividades por falta de investimento e capacitação, optou-se por fazer dois tipos de pesquisa: um estudo de caso com abordagem qualitativa na escola Rotary, por meio do projeto Sintonia da Educação. Para Yin (2001) o estudo de caso é uma forma de olhar para realidade reunindo informações numerosas e detalhadas para compreender a totalidade de informações de acontecimentos contemporâneos, e neste caso, o rádio como recurso pedagógico na escola. O que o diferencia de outras pesquisas históricas é a sua capacidade de lidar com uma ampla variedade de evidências, como documentos, artefatos, entrevistas e observações. Nesta perspectiva, foram analisados os roteiros dos programas e as radionovelas desenvolvidas pelos participantes do projeto e ouvido os professores que trabalhavam diretamente com a iniciativa. O Sintonia da Educação é um projeto de Educação Fiscal da Escola Rotary iniciado em 2015, que utiliza o rádio como ferramenta pedagógica de ensino. O objetivo é proporcionar no ambiente escolar, momentos de discussão e informação acerca da educação fiscal e das diversas temáticas de cunho social presentes na sociedade brasileira. Segundo Farias (2019), antes do Sintonia da Educação, a escola difundia os programas do Rádio Pela Educação, que eram transmitidos pela Rádio Rural de Santarém. Porém, sentiu-se a necessidade de a escola criar seus próprios programas de rádio com as temáticas que eram interessantes para os adolescentes e para as crianças atendidas pelo educandário. Na escola Madre Imaculada desenvolveu-se uma pesquisa participante, visto que o projeto Fala Galera! é uma iniciativa de dois professores da escola, os quais solicitaram apoio para a criação dos programas de rádio e formação da equipe que iria conduzir o projeto. Segundo Gil (2002) a pesquisa participante se caracteriza pela interação entre pesquisadores e membros das situações investigadas, ou seja, consiste na imersão do pesquisador no campo de estudo a ser investigado. Desta forma, o primeiro passo foi o reconhecimento da escola, seguido do conhecimento do 


\section{Revista Docência e Cibercultura}

projeto de rádio feito por meio de reunião com os professores responsáveis pela proposta, e identificado o espaço e os equipamentos disponíveis. Feito o diagnóstico inicial, fizeramse algumas sugestões e deu-se início as oficinas de formação. Foram oito encontros, os quais focaram a história do rádio, a linguagem radiofônica, técnicas de locução, técnicas de produção de roteiro e apresentação de programas. Também foram feitas entrevistas com alunos e professores envolvidos diretamente, e observações sobre o desenvolvimento da iniciativa, verificando a aceitação por parte do grupo docente e alunos da escola. $\mathrm{O}$ “Fala, Galera!” é um projeto de Rádio Escolar da Escola Madre Imaculada, que tem como objetivo "integrar currículo e práticas sociais à cultura digital vivenciada pelos interlocutores da locução e humanizar a formação e as condições de trabalho do professor". Os primeiros passos foram dados pela professora Joelma Portugal Freitas, que em suas aulas de Língua Portuguesa estimulou os alunos a produzirem programas de rádio para serem apresentados no horário do recreio, como atividade de conclusão da disciplina. $\mathrm{Na}$ Escola Rotary identificou-se que o Sintonia da Educação é parte do Projeto Político Pedagógico da Escola (PPP) e no início de cada ano os professores são capacitados para o uso da mídia em sala de aula. Os professores identificaram que o programa ajudou no desempenho tanto dos alunos envolvidos diretamente no projeto, quanto das crianças e adolescentes que acompanham o programa em sala de aula. Entre as melhorias ressaltadas estão a abertura para falar de temas complexos como violências sexual, física e psicológica (bullying), e melhoria na escrita, leitura, o aumento de interesse pela pesquisa, bem como o relacionamento em sala de aula. Já na escola Madre Imaculada verificou-se que o projeto ainda é visto como uma ação de dois professores, e ainda não faz parte do PPP do educandário. Porém, percebeu-se avanços como, por exemplo, a redução da timidez, a melhoria da oratória. Essa percepção foi possível durante as entrevistas, visto que nas oficinas eles pouco falavam, e tinham receio de participar das atividades. Além disso, os jovens ganharam autonomia. Verificou-se ainda que na escola Rotary, por exemplo, há carência de recursos financeiros para a compra de materiais necessários ao desenvolvimento da atividade do projeto Sintonia na Educação, e os professores foram capacitados para o uso da mídia pela própria escola, e por atores externos, visto que a 


\section{Revista Docência e Cibercultura}

Secretaria de Educação do município não dispõe de profissional capacitado para atender tal demanda. Já escola Madre Imaculada, embora tenha equipamentos disponíveis e uma sala preparada para a produção e veiculação dos programas de rádio, nem todos os professores foram capacitados para a utilização desta mídia como recurso de ensino em sala de aula, ou mesmo para uso de tecnologias, o que acaba prejudicando o andamento da proposta. Assim, ao estudar o uso do rádio na escola percebe-se que mesmo em meio a tantas tecnologias disponíveis, a mídia ainda apresenta potencialidades como recurso pedagógico, não apenas em sala de aula, mas em todo o espaço escolar, especialmente onde há carência de recursos financeiros. Percebe-se que a rádio escolar se apresenta como uma potencialidade que dá aos jovens a oportunidade de serem protagonistas de seu próprio aprendizado, pois podem pesquisar, produzir e transmitir as informações obtidas para toda a escola. Informações estas, que posteriormente serão trabalhadas na sala de aula com a mediação do professor. Nesta perspectiva, os estudantes compreendem que a escola, mais do que um lugar de "disciplina” e repasse de lições tiradas dos livros didáticos, é um espaço de diálogo, pesquisa e produção do conhecimento. No entanto, é importante que esta mídia tão importante para os povos da Amazônia se consolide como uma política pública dos governos, para que mais jovens e crianças tenham a oportunidade de usufruila nos espaços escolares, e que haja formação para os professores a fim de tenham habilidades e competências necessárias para mediar a aprendizagem dos estudantes contribuindo para a formação de uma consciência crítica.

Palavras-chaves: Rádio-escolar. Educomunicação. Santarém. Escolas públicas. Inclusão Sociodigital.

\section{Referência}

AZEVEDO, Lia Calebre de. No tempo do Rádio: Radiodifusão e cotidiano no Brasil 1923 - 1960. Rio de Janeiro, 2002. 
BALTAR, Marcos. Rádio Escolar: uma experiência de letramento midiático. 1.ed. São Paulo: Cortez, 2012.

BRANDÃO, Carlos Rodrigues. O que é educação. São Paulo: Brasiliense, 2007.

BORDENAVE, Juan E. Díaz. O que é comunicação. 3 ed. São Paulo: Brasiliese, 1997.

CASTELLS, Manuel. A sociedade em rede: do conhecimento à ação política. Rio de Janeiro: Casa da Moeda, 2006.

CITELLI, Adilson Odair. COSTA, Maria Cristina Castilho. Educomunicação: construindo uma nova área do conhecimento. São Paulo: Paulinas, 2011.

CONSONI, Marciel. Como usar o rádio na sala de aula. São Paulo: Contexto, 2007.

DEL BIANCO, Nélia. KLÖCKNER, Luciano. FERRARETTO, Luiz Artur. (org). 80 anos das rádios Nacional e MEC. In: DEL BIANCO, Nélia. PINHEIRO, Elton Bruno Barbosa. Porto Alegre: EDIPUCRS, 2017. P. 12 - 32.

FERRARETTO, Luiz Artur. Rádio: teoria e prática. São Paulo: Summus, 2014.

FREIRE, Paulo. Conscientização e prática da libertação: uma introdução ao pensamento de Paulo Freire. São Paulo: Cortez e Moraes, 1979.

FREIRE, Paulo. Extensão ou comunicação. $8^{\text {a }}$ ed. Rio de Janeiro: Paz e Terra, 1983.

FREIRE, Paulo. Pedagogia da Autonomia: sete saberes necessários à prática educativa. São Paulo: Paz e Terra, 1996.

FREIRE, Paulo. Política e Educação. 5.ed. São Paulo. Cortez, 2001.

FILHO, André Barbosa. Gêneros radiofônicos: os formatos e os programas em

GIL, Antônio Carlos. Métodos e técnicas de pesquisa social. 6.ed. São Paulo: Atlas, 2008.

GIL, Antônio Carlos. Como elaborar projeto de pesquisa. 4.ed. São Paulo: Atlas, 2002.

GOLDENBERG, Mirian. A arte de pesquisar: Como fazer pesquisa qualitativa em Comunicação Social. 1ed. Rio de Janeiro. Record, 2015.

KAPLÚN, Mário. Una pedagogía de la comunicación. Madri: De la Terra, 1988.

KLOCKNER, Luciano. FERRARETTO, Luiz Arthur. E o rádio? Novos horizontes midiáticos. In: RIBEIRO, Adriana Gomes. Rádio Educação - maneiras de conjugar. Porto Alegre: Edipucrs, 2010. P. 286 - 300 


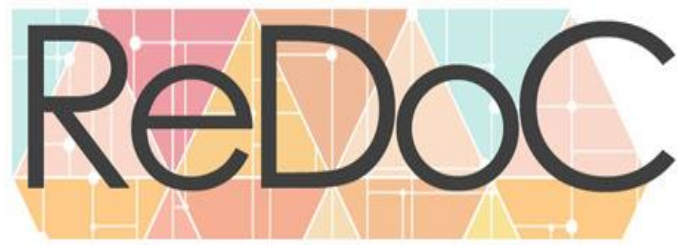

\section{Revista Docência e Cibercultura}

KUNSCH, Margarida Maria Krohling. Comunicação e educação caminhos cruzados. Loyola: São Paulo, 1986.

LAKATOS, Eva Maria; MARCONI, Marina de Andrade. Fundamentos de metodologia científica. $7^{\text {a }}$ Ed. São Paulo: Atlas, 2010.

LÜDKE, Menga. MARLI, E. D. A. André. Pesquisa em educação: abordagens qualitativas. São Paulo, Epu, 1986.

MARTIN-BARBERO, Jesús. A Comunicação na educação. São Paulo: Contexto, 2014.

MOREIRA, Sonia Virgínia (org). 70 anos de radiojornalismo no Brasil 1941 - 2011. In: COSTA, Luciana Miranda. Aonde só o rádio chega. Rio de Janeiro: EdUERJ, 2011. P. $293-304$.

NAGAMINI, Eliana (org). Questões teóricas e formação profissional em comunicação e educação. In: ROMANCINI, Richard. Comunicação e educação as distintas trajetórias no espaço ibero-americano. Vol. 1. Bahia: ESC, 2016. P. 23 - 42.

NAGAMINI, Eliana. Questões teóricas e formação profissional em comunicação e educação. In: SILVA, Camila de Alvarenga Assis. Vol. 1. Bahia: ESC, 2016. P. 55 -In 69.

NAGAMINI, Eliana. Questões teóricas e formação profissional em comunicação e educação. In: CORAZZA, Helena. Vol. 1. Bahia: ESC, 2016. P. 128 - 144.

NEUBERGER, Rachel Severo Alves. O Rádio na Era da Convergência das Mídias. Cruz das Almas/BA: UFRB, 2012.

OROZCO GÓMES, Guillermo. Educação: recepção midiática, aprendizagem e cidadania. São Paulo: Paulinas, 2011.

ORTRIWANO, Gisela Swetlana. A Informação no rádio: os grupos de poder e a determinação dos conteúdos. São Paulo: Summus, 1985.

PRADO, Magaly. História do Rádio no Brasil. São Paulo: Da Boa Prosa, 2012.

PRETTO, Nelson de Luca. TOSTA, Sandra Pereira (org.) Do MEB à WEB: o rádio na Educação. In: FILHO, José Peixoto. O Rádio e a Educação: A experiencia do MEB e as contribuições para a educação popular. Belo Horizonte: Autêntica Editora, 2010.

PEREIRA, José Haroldo. Curso básico de Teoria da Comunicação. $4^{\text {a }}$ ed. Rio de Janeiro: Quartet, 2007. 
PEREIRA, José Haroldo. Do MEB à WEB: o rádio na Educação. In: PRETTO, Nelson de Luca. BONILLA, Maria Helena Silveira. SARDEIRO, Carla. Rádio web na educação: possibilidades e desafios.

RABAÇA, Carlos Alberto. BARBOSA, Gustavo Guimarães. Dicionário essencial de comunicação. $1^{\text {a }}$ ed. Rio de Janeiro: Lexikon, 2014.

RODRIGUES, Adriano Duarte. Estratégias da Comunicação. $2^{\mathrm{a}}$ Ed. Lisboa: Editorial Presença, 1997.

RODRIGUES, Rosa Luciana de. Rádio Popular na Amazônia: o processo comunicacional do Projeto Rádio Pela Educação. UFPA, 2012.

SANTAELLA, Lúcia. Comunicação e Pesquisa. São Paulo: Hacker, 2001.

SCHLESENER, Anita Helen. Marxismo(s) e educação (Locais do Kindle 794-795). SciELO - Editora UEPG. Edição do Kindle.

SOARES, Ismar de Oliveira. Educomunicação: contribuições para a reforma do ensino médio. $3^{\text {a }}$ ed. São Paulo: Paulinas, 2011.

SODRÉ, Muniz. Antropológica do Espelho: Uma teoria da comunicação linear e em rede. 7ed. Petrópolis, RJ: Vozes, 2012.

WOLTON, Dominique. É preciso salvar a comunicação. São Paulo: Paulus, 2006.

YIN, Roberto K. Estudo de caso: Planejamento e métodos I. 2ed. Porto Alegre. Bookman, 2001.

ZUCULOTO, Valci. LOPEZ, Débora. KISCHINHEVSKY, Marcelo (org). Estudos Radiofônicos no Brasil: 25 anos do grupo de pesquisa Rádio e Mídia Sonora da Intercom. In: AMARANTE, Maria Inês. O papel do rádio na educação e no desenvolvimento local. Experiências marcantes no Brasil e em outros países da América Latina. E-books 22. São Paulo: Intercom, 2016.

Este é um artigo de acesso aberto distribuído sob os termos da Licença Creative Commons Atribuição Não Comercial-Compartilha Igual (CC BY-NC- 4.0), que permite uso, distribuição e reprodução para fins não comerciais, com a citação dos autores e da fonte original e sob a mesma licença. 